\title{
BMJ Open Forecasting the SARS COVID-19 pandemic and critical care resources threshold in the Gulf Cooperation Council (GCC) countries: population analysis of aggregate data
}

Amira K Al-Aamri, ${ }^{1}$ Ayaman A Al-Harrasi, ${ }^{2}$ Abdurahman K AAl-Abdulsalam, ${ }^{3}$ Abdullah A Al-Maniri, ${ }^{4}$ Sabu S Padmadas (D) ${ }^{5}$

To cite: Al-Aamri AK, AlHarrasi AA, AAl-Abdulsalam AK, et al. Forecasting the SARS COVID-19 pandemic and critical care resources threshold in the Gulf Cooperation Council (GCC) countries: population analysis of aggregate data. BMJ Open 2021;11:e044102. doi:10.1136/ bmjopen-2020-044102

- Prepublication history and additional supplemental material for this paper are available online. To view these files, please visit the journal online (http://dx.doi.org/10.1136/ bmjopen-2020-044102).

Received 22 August 2020 Revised 20 April 2021 Accepted 23 April 2021

Check for updates

(C) Author(s) (or their employer(s)) 2021. Re-use permitted under CC BY-NC. No commercial re-use. See rights and permissions. Published by BMJ.

For numbered affiliations see end of article.

Correspondence to

Professor Sabu S Padmadas;

S.Padmadas@soton.ac.uk

\section{ABSTRACT}

Objective To generate cross-national forecasts of COVID-19 trajectories and quantify the associated impact on essential critical care resources for disease management in Gulf Cooperation Council (GCC) countries.

Design Population-level aggregate analysis.

Setting Bahrain, Kuwait, Oman, Qatar, United Arab Emirates (UAE) and Saudi Arabia.

Methods We applied an extended time-dependent SEICRD compartmental model to predict the flow of people between six states, susceptible-exposed-infectedcritical-recovery-death, accounting for community mitigation strategies and the latent period between exposure and infected and contagious states. Then, we used the WHO Adaptt Surge Planning Tool to predict intensive care unit (ICU) and human resources capacity based on predicted daily active and cumulative infections from the SEICRD model.

Main outcome measures Predicted COVID-19 infections, deaths, and ICU and human resources capacity for disease management.

Results COVID-19 infections vary daily from 498 per million in Bahrain to over 300 per million in UAE and Qatar, to 9 per million in Saudi Arabia. The cumulative number of deaths varies from 302 per million in Oman to 89 in Qatar. UAE attained its first peak as early as 21 April 2020, whereas Oman had its peak on 29 August 2020. In absolute terms, Saudi Arabia is predicted to have the highest COVID-19 mortality burden, followed by UAE and Oman. The predicted maximum number of COVID-19-infected patients in need of oxygen therapy during the peak of emergency admissions varies between 690 in Bahrain, 1440 in Oman and over 10000 in Saudi Arabia.

Conclusion Although most GCC countries have managed to flatten the epidemiological curve by August 2020, trends since November 2020 show potential increase in new infections. The pandemic is predicted to recede by August 2021, provided the existing infection control measures continue effectively and consistently across all countries. Current health infrastructure including the provision of ICUs and nursing staff seem adequate, but health systems should keep ICUs ready to manage critically ill patients.
Strengths and limitations of this study

- Overall, barring a few fluctuations, the difference between the observed and predicted number of deaths in the SEICRD (susceptible, exposed, infected, critical, recovered, death) model is generally marginal across the Gulf Cooperation Council (GCC) countries.

- The predictions are based on public health interventions prevailing at the time, and the assumptions that the populations under investigation are stable, asymptomatic population exposed are infectious and those confirmed COVID-19-positive will have no reinfections and there are no changes in intensive care unit (ICU) resources during COVID-19.

- The Adaptt Surge Planning Tool predictions of ICU resources apply to inpatient care only.

- Lack of availability of demographic and socioeconomic data restricts our understanding of the infection dynamics.

- Given the high representation of expatriate population across GCC countries, further analysis disaggregated by nationality is pertinent to understand the differential impact of COVID-19 on population subgroups.

\section{INTRODUCTION}

The pace and magnitude of the novel, highly contagious severe acute respiratory syndrome (SARS) COVID-19 pandemic outbreak vary substantially across world regions. COVID19 , first reported in the Wuhan region of China, ${ }^{12}$ spread rapidly to European countries of Italy, Spain and the UK, and in North and Latin America including USA, Canada and Brazil. ${ }^{3-5}$

COVID-19 pandemic outbreak in Gulf Cooperation Council countries

Within the Gulf Cooperation Council (GCC) countries, United Arab Emirates (UAE) reported the first four cases as early as 29 
January 2020, and other GCC countries including Saudi Arabia, Oman, Bahrain, Qatar and Kuwait reported their first few cases towards the end of February $2020 .{ }^{467}$ Since then, the new COVID-19 infections and deaths have more than doubled within the GCC region. For example, the weekly total number of new infections in GCC countries has doubled from 25965 for the week of May 3-9 to 51 713 for the week of June 21-27, whereas the number of deaths per week increased from 144 to 393 during the same period. Saudi Arabia, the most populous country within GCC, has been the worst affected in terms of the total number of positive cases and case fatalities. ${ }^{8}$

\section{Government response and the wider socioeconomic and healthcare context}

While most GCC countries responded early to disease control and prevention in terms of enforcing social distancing, lockdown, public health awareness and behavioural change campaigns, ${ }^{9}$ the implementation was transient and inconsistent due to economic and demographic challenges. As countries prepare to face another global economic recession post-COVID-19, the situation is exacerbated in GCC countries severely affected by the recent oil crash. ${ }^{1011}$ COVID-19 has also extensively disrupted national economic diversification plans and functioning of small and medium industries and businesses in the GCC region. On average, two-thirds of GCC population represent young expatriate workers, working mostly in services and construction sectors, and they live in congested accommodation, often with low wages. ${ }^{12}$ The share of expatriate population is the highest in UAE and Qatar (over 80\%) and lowest in Saudi Arabia (33\%). ${ }^{12}$

Data from respective government ministries show a disproportionately higher incidence of COVID-19 infections and deaths among expatriate workers. However, these data are currently unavailable for research use in GCC countries. Older people aged 65 and above constitute between 3.3\% in Saudi Arabia and 2\% or less in the rest of GCC countries, which partly explain the anomaly between high incidences of COVID-19 infections and low case fatalities in the region.

On the other hand, GCC countries have high rates of non-communicable and chronic diseases including ischaemic and coronary heart diseases, obesity, hypertension and diabetes mellitus. ${ }^{13} 14$ GCC countries spend, on average, $4.3 \%$ of their gross domestic product on healthcare, ranging between 5.8\% in Saudi Arabia and 3.1\% in Qatar, mostly for treatment and management of noncommunicable and chronic diseases. ${ }^{12}$

\section{Research gap}

Except for a few review and clinical studies, ${ }^{915}$ there is no clear understanding of the future trends of COVID-19 in GCC countries and their impact on critical care capacity for disease management. As of 31 July 2020, GCC countries with a combined population of 58.5 million have conducted a total of 10.6 million tests and identified 631 628 positive cases, and of these 558693 (88\%) recovered and $4400(0.7 \%)$ died. $^{8}$ The number of new cases reported every day at that time remained high in the GCC region, particularly in Saudi Arabia.

The current pandemic situation is rather uncertain in GCC countries, especially with no systematic data on emergency admissions and adequate population-level testing. The potential (subsequent) peaks of the pandemic are uncertain and there is little consensus on resource allocation for emergency care, including intensive care unit (ICU) beds and ventilator support, in the event of further increase and new wave of infections.

\section{Research question}

Our main research question is: how can we systematically compare and forecast the trends in COVID-19 pandemic across GCC countries and what are the implications of these trends on critical care resources capacity at the national level? The goal of this article is to apply forecasting techniques to investigate the evolution of the COVID-19 pandemic and quantify the critical care resource threshold for infection control and management in GCC countries.

\section{Contributions}

In the light of aforementioned research and data gaps, this paper contributes a case study documenting the current and future trajectories of the COVID-19 pandemic and associated implications comparing the six GCC countries. The findings of this paper have implications for designing universal public health policies and interventions in the region, especially given the geographical proximity and population movements between GCC countries. The paper highlights the challenges associated with the paucity of existing data and calls for coordinated efforts to share reliable and consistent information in the region.

\section{MATERIALS AND METHODS}

We considered a systematic approach to find the best model to predict the future evolution of the COVID-19 pandemic and hospital resources capacity threshold in GCC countries.

\section{Data}

The key input variables for mathematical forecasting included confirmed COVID-19-positive infection cases and deaths. These data derived from various sources including the Johns Hopkins Coronavirus Center, ${ }^{4}$ Our World in Data, ${ }^{7}$ WHO, ${ }^{3}$ GCC Stat $^{8}$ and the respective ministries of individual countries and were verified for consistency.

\section{Modelling approach and assumptions}

We extended the widely used SIR (susceptible, infected and recovered) compartmental mode ${ }^{16}$ by including variants ${ }^{6} 17-22$ to develop an SEICRD model taking into account community mitigation strategies and the latent period between when a person is actually exposed and 
Table 1 COVID-19 testing, confirmed cases, recovered and deaths in GCC countries

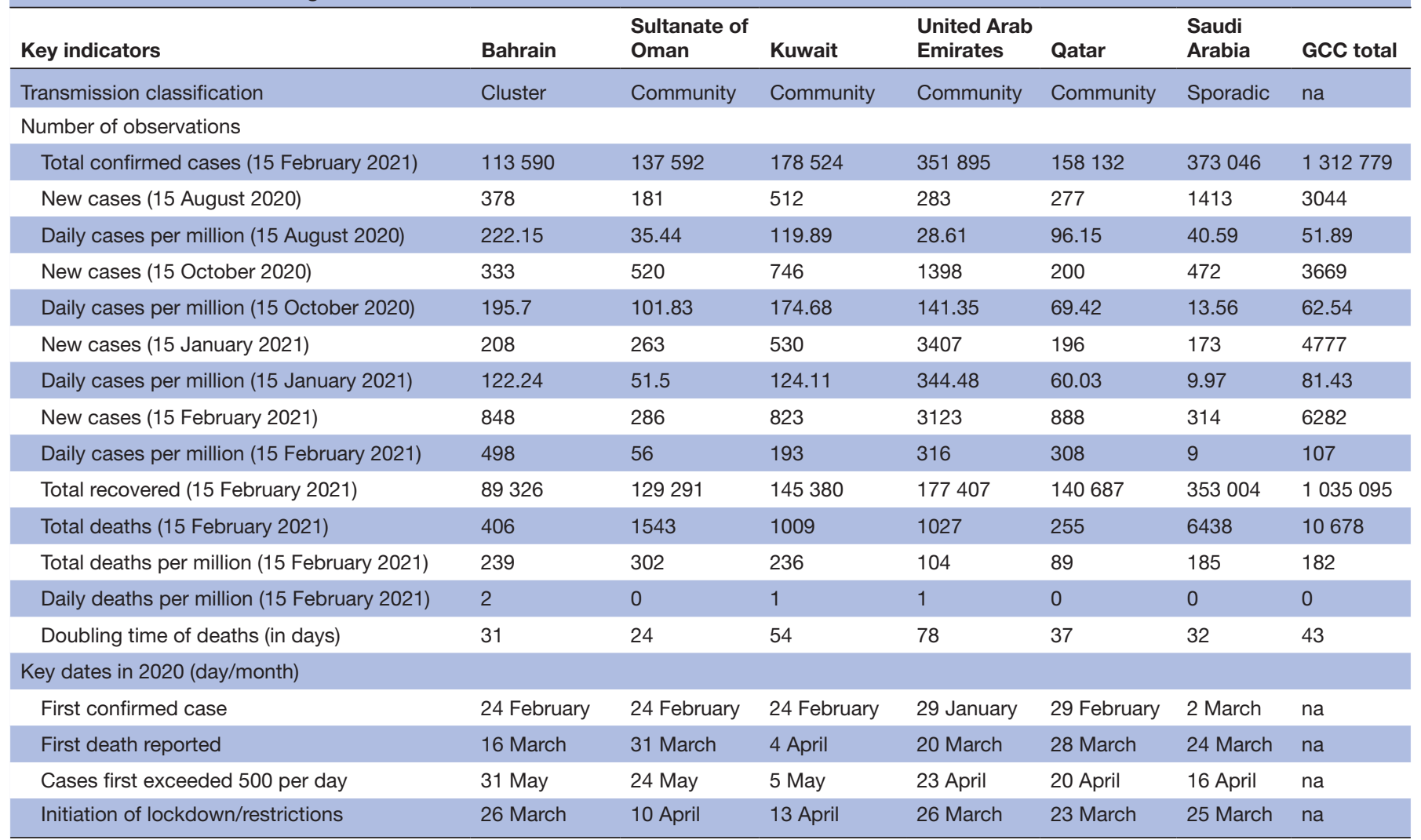

Source: Compiled from WHO, ${ }^{3}$ Johns Hopkins Center for Systems Science and Engineering, ${ }^{4}$ Our World in Data, ${ }^{7}$ and GCC Stats. ${ }^{6}$ Last updated: 28 February 2021.

GCC, Gulf Cooperation Council; na, not applicable.

until infected and contagious. The SEICRD model incorporates the transition of individuals between six states (online supplemental figure S1). The states include susceptible (S): number of individuals susceptible to be exposed; exposed (E): number of individuals exposed where the disease status is latent, and individuals are infected but not infectious yet; infected (I): number of individuals actually infected and infectious; critical (C): infected individuals who need intensive care; recovered (R): number of infected who recover with an assumed lifelong immunity and do not return to the susceptible (S) state; and the absorbing state death (D).

We assumed that the population is stable, there are no reinfections of people who already had the infection, and there are no changes in the size and composition of ICU resources during COVID-19. The input data included the number of ICU beds per 100000 population, proportion of population by age group, transition probabilities from infected to critical, and critical to dead, and the number of confirmed cases and deaths per day by country. The analysis was conducted in Python Jupyter V.3.7.6. ${ }^{23}$ The mathematical equations to predict the outcomes of the SEICRD model are described in detail elsewhere. ${ }^{24}$

The SEICRD model predicts the number of ICU beds needed to treat COVID-19 critical cases, taking into account the predicted number of patients with critical conditions and existing bed capacity. Suppose that a given country has $B$ number of ICU beds to treat $C_{N}$ coronavirus cases with critical condition. If the number of critically ill patients $\left(C_{N}\right)$ exceeds the number of ICU beds $(B)$, then we will have $\left(C_{N}-B\right)$ critical cases that cannot be treated, and hence the patient may die due to the shortage in the number of ICU beds. However, if $B$ is greater than $C_{N}$, then all critical cases have the chance to be treated. ${ }^{24}$

The predicted number of cases in need of critical care, critical cases requiring oxygen and mechanical ventilation, extracorporeal membrane oxygenation (ECMO) and renal replacement therapy (RRT), and nursing resources and specialised medical practitioners were estimated using the WHO Adaptt Surge Planning Tool. ${ }^{25}$ The input parameters for the Adaptt Tool were based on the outputs from the SEICRD model: daily predicted active infected, daily predicted new infected and cumulative infected cases. In the Adaptt Tool, we selected the option very low scenario ${ }^{25}$ attack rate $(5 \%)$, which represents the percentage contracting COVID-19 at the population level, and a universal social distancing mitigation measure. The infection transmission rates have been relatively slower across GCC countries.

The Adaptt model predicts the future ICU beds needed by date for treating patients with moderate, severe and critical symptoms including ECMO and RRT and the human 
resources needed. Note the Adaptt model only considers inpatient care. It takes into account the number of nurses required per shift and the shift configuration for treating patients with COVID-19. The tool enables users to input epidemiological data and generate mitigation scenarios for hospital resources planning and decision-making. It classifies patients into mild, moderate, severe and critical categories according to the level of resources needed. ${ }^{20}$ Those classified mild can recover at home without inpatient care, moderate require inpatient care, severe require inpatient care with oxygen therapy, and critical patients require inpatient care with mechanical ventilation.

\section{Patient and public involvement}

There was no patient and public involvement.

\section{RESULTS}

\section{COVID-19 trends and national interventions in GCC countries} since the outbreak

Four out of six GCC countries confirmed COVID-19 transmission at the community level, whereas clusters of cases were reported in Bahrain and sporadic transmission in Saudi Arabia (table 1). The number of new confirmed cases of COVID-19 has fallen across GCC countries since August 2020 until early February 2021. However, data during mid-February 2021 show the opposite, with a significant increase in the number of new cases in all countries.

Population-level infection control measures, including social distancing, lockdown, curfew and movement restrictions, appear to have had perceptible effects only in UAE initially and in Qatar and Saudi Arabia, whereas similar measures in other countries seem ineffective or inconsistent (figure 1). As of February 2021, the number of national lockdowns implemented has varied from 27 in Qatar, 24 in UAE, 20 in Kuwait, 13 in Bahrain and Saudi Arabia, to 5 in Oman, whereas the number of curfews and movement restrictions varied between 194 in Qatar to 39 in Oman. ${ }^{26}$

As illustrated in terms of weekly average trends, Oman, Bahrain, Kuwait and Saudi Arabia recorded a steady increase in new cases until mid-June. Figure 1 clearly demonstrates evidence of early flattening of the epidemiological curve in Qatar and UAE, although there are signs of potential new wave in these countries. Bahrain and Kuwait are currently (as of February 2021) approaching a potential second wave.

Our data investigations show that the number of daily tests carried out was the lowest in Oman and Kuwait $(<1$ per 1000 population) and highest in Bahrain and UAE. Saudi Arabia has the lowest testing rates proportionate to population size. Population-level testing for COVID-19 infections has been disrupted, and most countries have confined testing to people with symptoms or those seeking institutional healthcare, especially emergency admissions. As of 15 February 2021, Saudi Arabia has recorded the highest recovery rate $(95 \%)$, followed by Oman (94\%) and Qatar (89\%), whereas UAE recorded the lowest recovery rate.

The total number of deaths varies between 302 per million population in Oman to slightly over 235 per million in Bahrain and Kuwait. Saudi Arabia has the

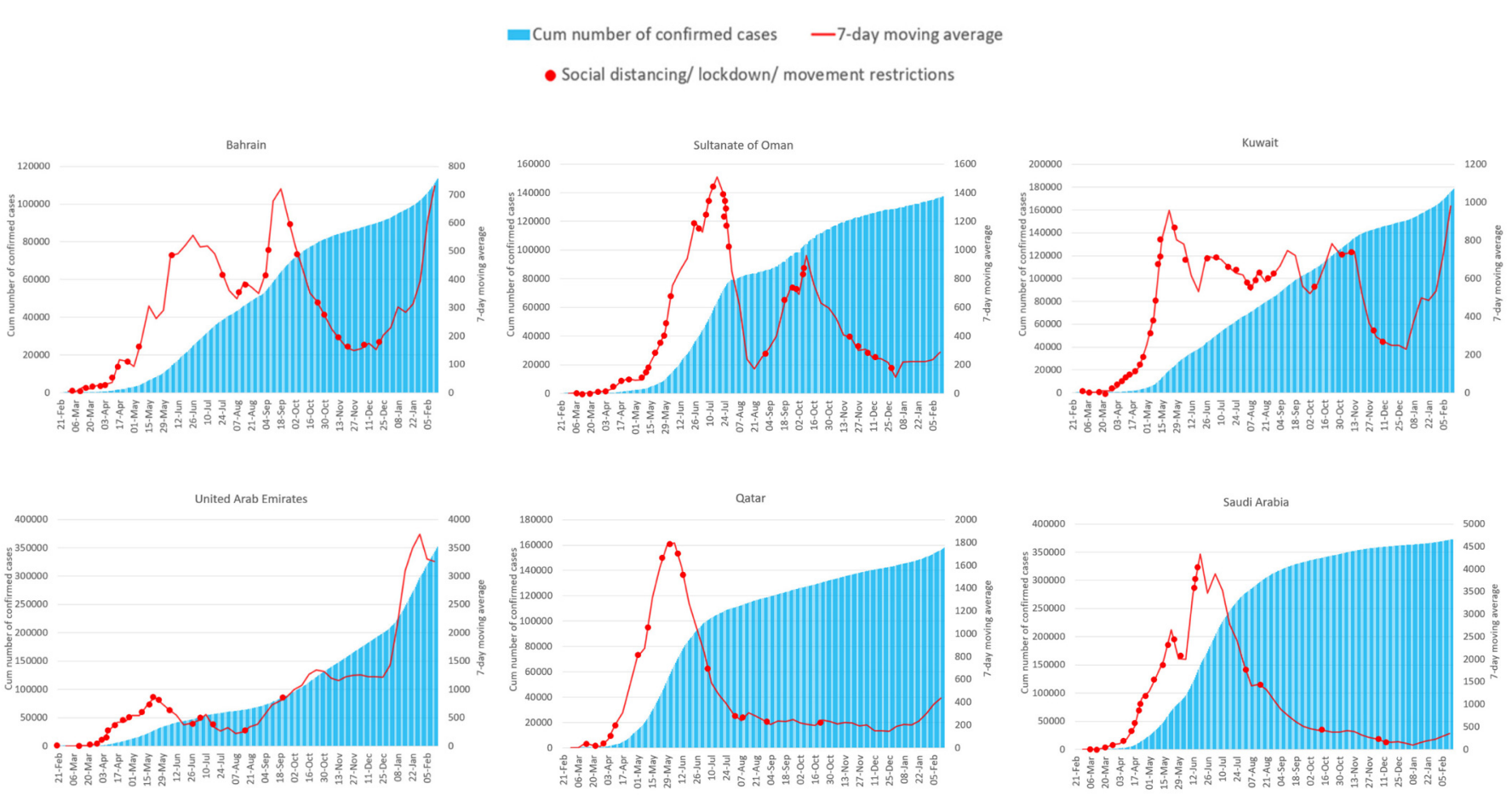

Figure 1 Number of COVID-19 confirmed cases from 21 February 2020 to 15 February 2021 in Gulf Cooperation Council countries. 
Table 2 Predicted cumulative number of COVID-19 events by date based on the SEICRD model

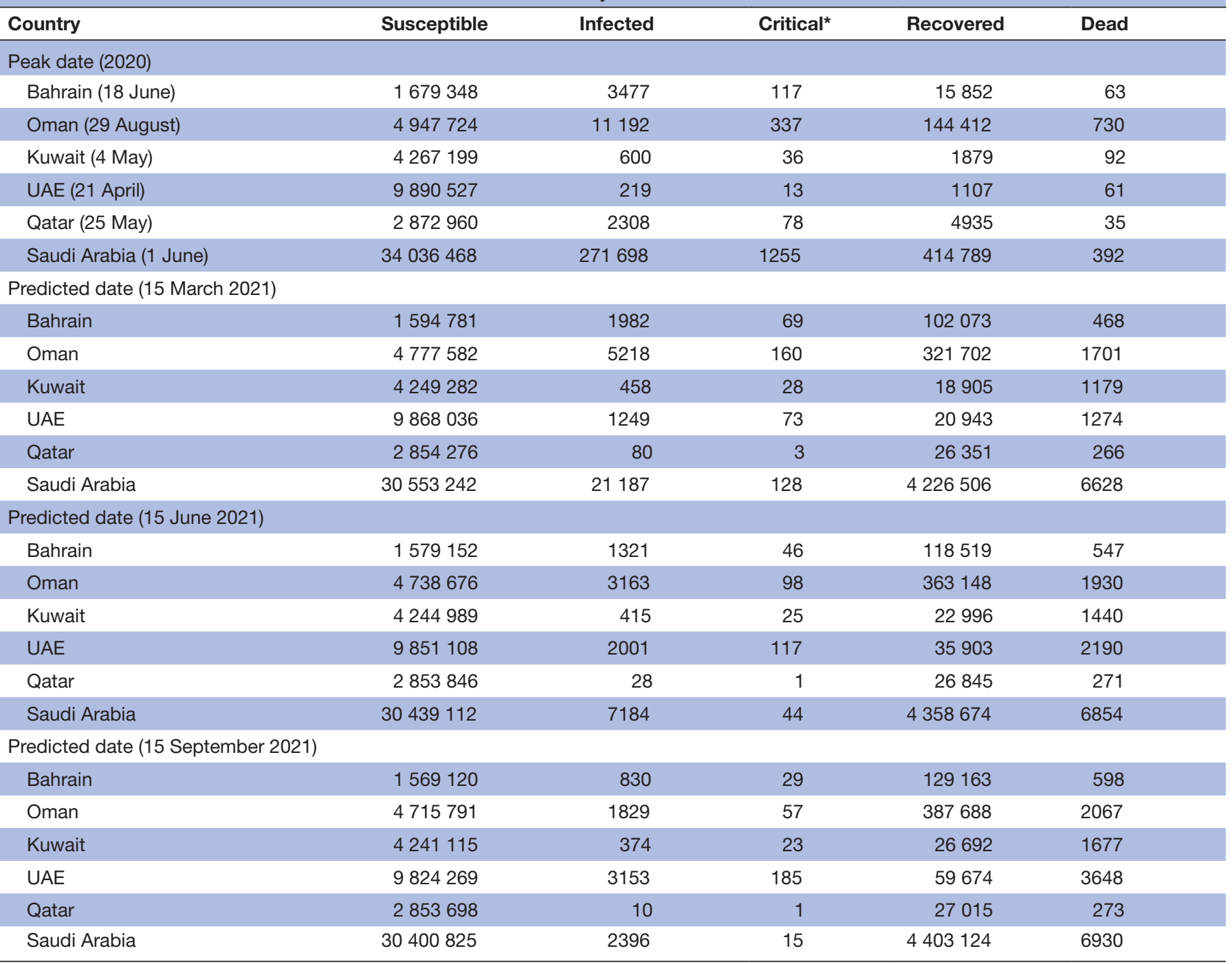

${ }^{*}$ Figures shown are non-cumulative.

SEICRD, susceptible, exposed, infected, critical, recovered, death; UAE, United Arab Emirates.

highest mortality burden in absolute terms at the population level. The doubling time for mortality at the initial stage of the pandemic varied between 24 and 31 days in Oman and Bahrain and 78 days in UAE.

\section{Future trajectories of COVID-19 in GCC countries}

The predicted future trends in COVID-19 based on the SEICRD compartmental model are summarised in table 2 . The predicted values are based on the probabilities of transition across different states from infected to critical, critical to dead and so on. Note the scale of population size varies by country: Bahrain: 1.69 million; Qatar: 2.80 million; Kuwait: 4.27 million; Oman: 5.01 million; UAE: 9.88 million; and Saudi Arabia: 34.79 million.

To illustrate, in Oman, on the peak date of the infection (29 August), of the 4.95 million people susceptible to COVID-19, 11192 were infected, 337 cases manifested severe or critical symptoms and 730 died (table 2). By 15 September 2021, Oman will have a predicted cumulative number of 2067 deaths and 57 needing critical care on that particular date.

The model estimates indicate that there are variations between GCC countries in terms of date of infection peak, with UAE as the first country in GCC to achieve a peak towards the end of April 2020. On the other end, Oman and Bahrain attained their peak on 29 August and 18 June, respectively. In absolute terms, Saudi Arabia is predicted to have the highest COVID-19 mortality burden (6930 deaths) by 15 September 2021, followed by UAE (3648) and Oman (2067 deaths). By then, GCC countries together will have a predicted 15193 deaths.

The fitted models were robust and there was little difference between the observed and predicted outcomes (figure 2). Overall, barring a few fluctuations in Bahrain and Kuwait, the difference between the observed and predicted number of deaths in the SEICRD model is marginal across GCC countries. In Bahrain, the model 

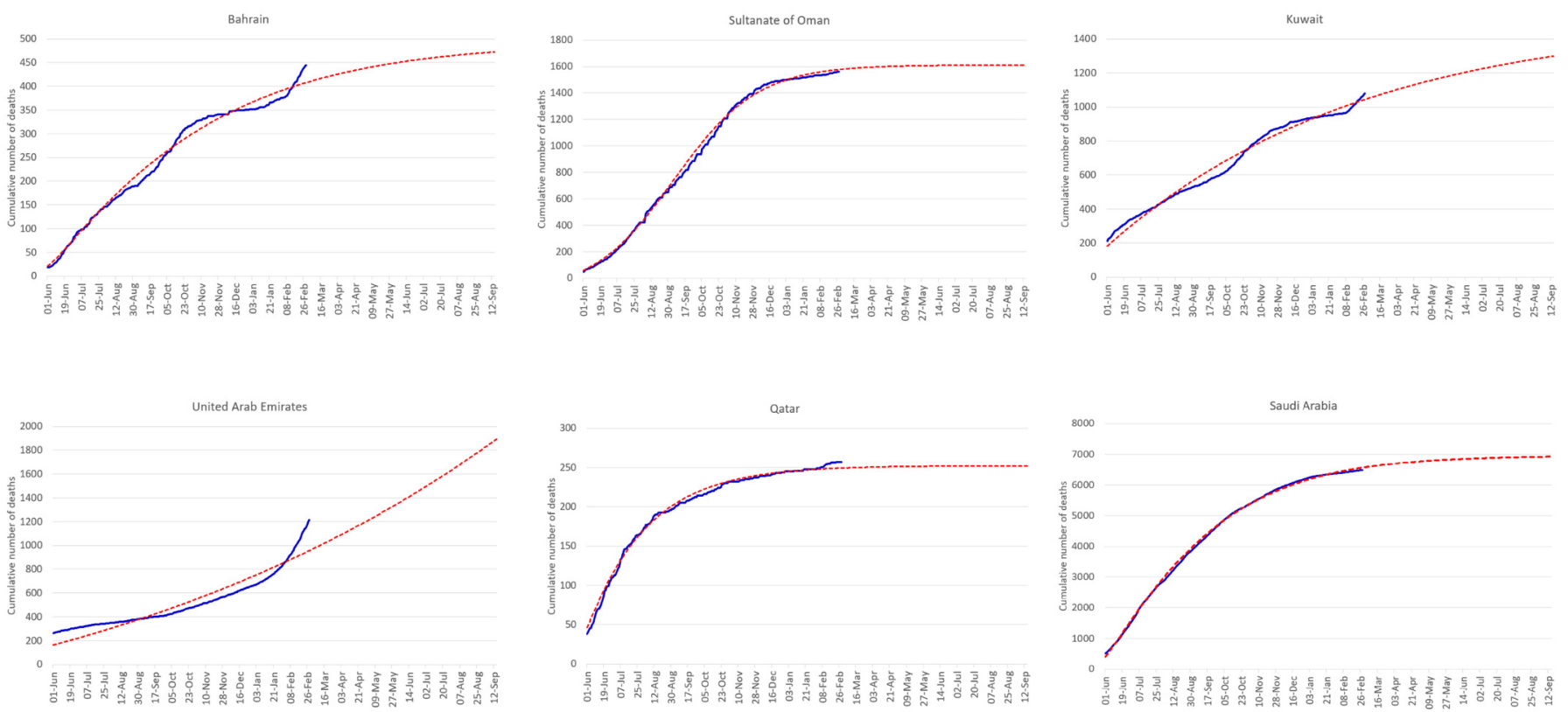

Figure 2 Observed and predicted cumulative number of COVID-19 deaths based on the SEICRD model in Gulf Cooperation Council countries (from 1 June 2020 to 15 September 2021). SEICRD, susceptible, exposed, infected, critical, recovered, death.

slightly overpredicted the deaths during the months of October-November 2020 and January-February 2021. In UAE, the model overpredicted the deaths between midNovember 2020 and January 2021 and underpredicted during June 2020.
The predicted ICU equipment capacity and human resources for COVID-19 management is graphically illustrated in figures 3 and 4, respectively. Note that due to technical reasons, we could not provide an update of the prediction beyond December 2020. The model assumes

\footnotetext{
- Cases in need of critical care - Severe cases in need of oxygen therapy

- Critical cases in need of mechanical ventilation -Critical cases in need of ECMO

- Critical cases in need of RRT
}
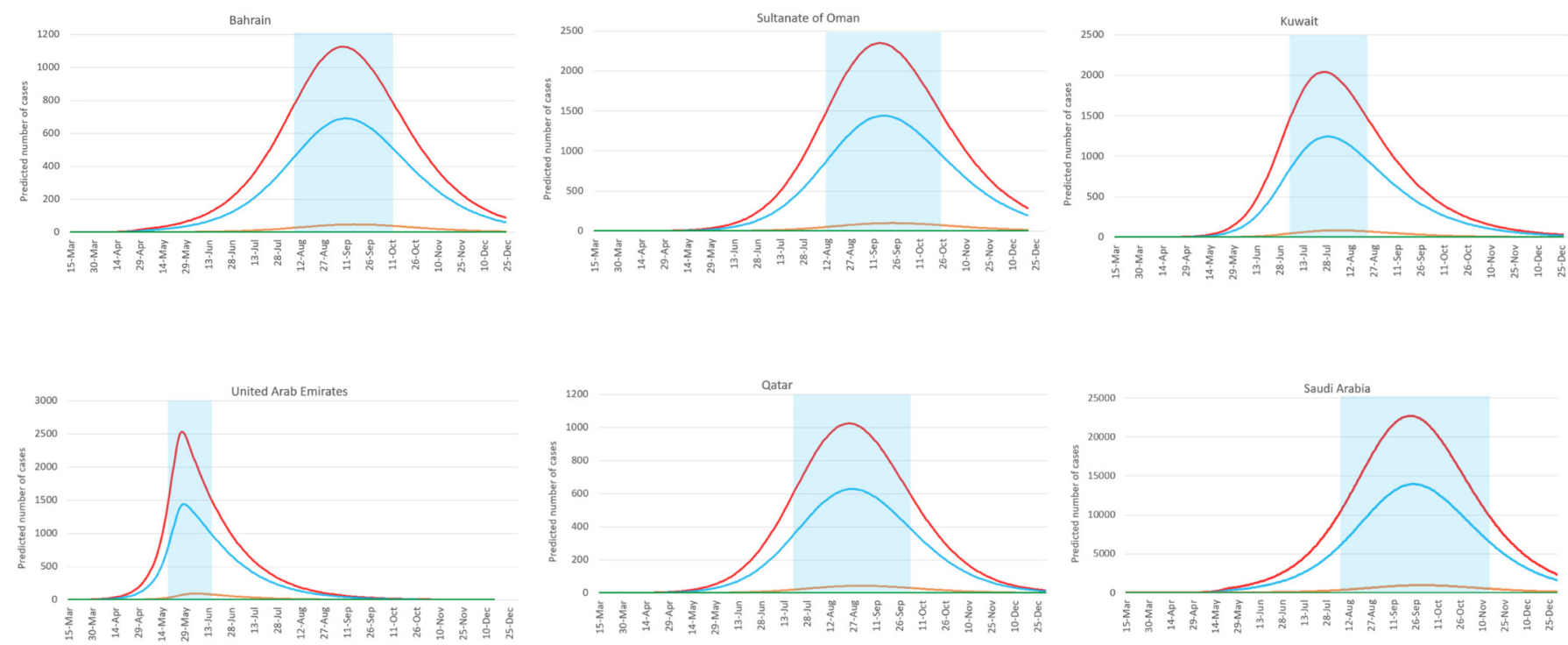

Figure 3 Predicted intensive care unit equipment capacity for COVID-19 management applying the SEICRD model estimates to the WHO Surge Planning Tool in Gulf Cooperation Council countries. ECMO, extracorporeal membrane oxygenation; RRT, renal replacement therapy; SEICRD, susceptible, exposed, infected, critical, recovered, death. 

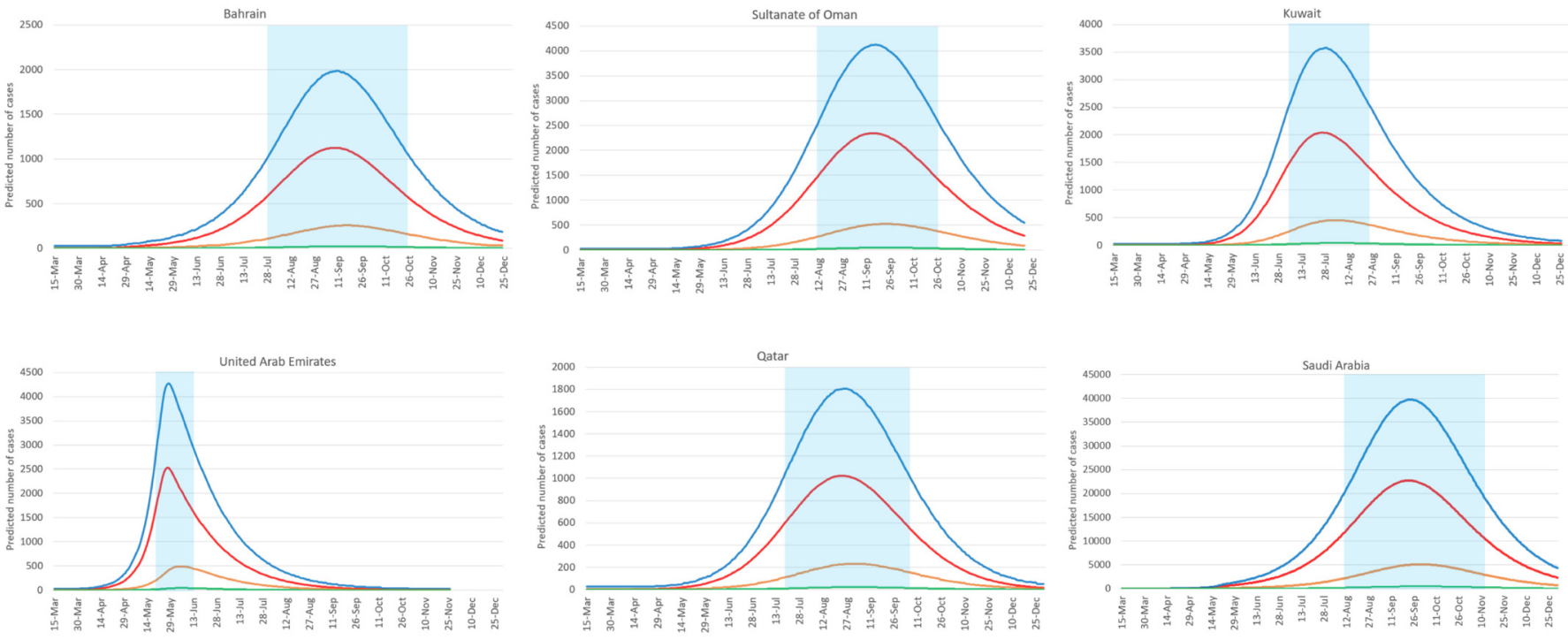

Figure 4 Predicted ICU human resources capacity for COVID-19 management applying the SEICRD model estimates to the WHO Surge Planning Tool in Gulf Cooperation Council countries. ICU, intensive care unit; SEICRD, susceptible, exposed, infected, critical, recovered, death.

that all active cases are detected at the population level, and also takes into account the lag between date of infection and date when symptoms become critical or severe. Note GCC countries are relatively well equipped with intensive care systems and human resources, and the existing systems are currently able to manage the COVID-19 pandemic without disruptions. However, the circumstances could change if the infections surge beyond the predicted levels.

The predicted number of infected persons requiring critical care during the peak of emergency admissions (area shaded in blue) is estimated to vary between 2000 and 22000 depending on the population exposed and actually infected. Those in need of oxygen therapy is predicted to vary between 690 in Bahrain, 1441 in Oman and over 10000 in Saudi Arabia (figure 3).

The demand for total nursing staff during the peak of emergency admissions is predicted to vary from 2000 in Bahrain and 4000 in Oman to as high as 40000 in Saudi Arabia (figure 4). However, Saudi Arabia has over 190000 nurses available within health systems. In comparison, Bahrain has 4254, UAE 56 375, Kuwait 31 602, Qatar 21 032 and Oman 21448 nurses currently in employment. ${ }^{78}$ The models predict a high demand for specialised ICU nurses during the peak of emergency admissions over the period from August to October in most countries, except UAE.

\section{Strengths and limitations of this study}

The analysis is the first of its kind in GCC countries to generate robust cross-national forecasts of COVID-19 and its impact on essential critical care resources for disease management. Overall, barring a few fluctuations, the difference between the observed and predicted number of deaths in the SEICRD model is generally marginal across GCC countries. The predictions are based on public health interventions prevailing at the time and the assumptions that the populations under investigation are stable, asymptomatic population exposed are infectious, those confirmed COVID-19 positive will have no reinfections and there are no changes in ICU resources during COVID-19.

The Adaptt Surge Planning Tool predictions of ICU resources apply to inpatient care only. Unfortunately, the tool does not allow to extend predictions beyond 365 days, and hence we could not present the predictions for future months. Furthermore, we could not validate these predictions with observed data due to lack of access to such information at the time of analysis.

Lack of availability of demographic and socioeconomic data restricts our understanding of the infection dynamics. Given the high representation of expatriate population across GCC countries, further investigation disaggregated by nationality is pertinent to understand the differential impact of COVID-19 on population subgroups.

\section{DISCUSSION}

The foregoing analysis yielded robust predictions based on the SEICRD model, comparing the trajectories of COVID-19 case incidence and mortality rates across GCC countries, and further quantified the demand for emergency care resources capacity. The scale and communitylevel spread of COVID-19 pandemic have been relatively less severe in GCC countries when compared with other 
economically advanced nations. ${ }^{3} 4$ The infection transmission was initially confined to small clusters during the early phase of the pandemic, and subsequently elevated to community level in most countries, with increased risk of transmission among expatriate workers living in labour camps and boarding houses near construction sites and service stations. The vast majority of expatriate workforce is engaged in front-line unskilled and casual work, living in harsh conditions with little income and subsistence.

Most countries in GCC are sparsely populated except in capital cities and adjacent small cities. Infection control measures including travel, international border control, international flight suspensions, ${ }^{9}$ quarantine, social and religious congregation restrictions, ${ }^{27}$ short curfews, social distancing, and lockdown initiated early had some effect in controlling the spread of infection, but appear to be not fully effective in most countries, including in Saudi Arabia which had the Middle East respiratory syndrome coronavirus outbreak in 2012. ${ }^{28}$ The number of COVID-19 positive cases showed a steady increase towards the end of May 2020, as people returned to work and resumed economic activities after the religious Eid holidays, and then subsequently the infections have been increasing since November. The most recent trends show a spike in the number of new cases across GCC countries, at a time when vaccinations are being gradually rolled out.

Our model-based predictions confirmed that UAE attained a peak towards the end of April 2020, and Bahrain and Oman by 18 June and 29 August, respectively. In absolute terms, Saudi Arabia has experienced the highest burden of COVID-19 mortality, followed by UAE and Oman.

These trends are predicted on the assumption that the current infection control measures prevail until the new infections are contained in small clusters, and with adequate testing and surveillance systems to trace, isolate and treat patients with COVID-19. It has become clear that GCC countries have not fully recovered from the pandemic, and new infections attributed to potentially newly mutated strain seem looming large in the region. The variations in infection trends depend on population characteristics: size, composition, density and the readiness of hospitals to manage critical cases.

Our predictions show that the demand for specialised ICU nurses have continued to remain high until October 2020 and further demand is likely to be determined depending on the increase in new cases. These predictions are based on the assumption that the current public health interventions continue with adequate surveillance systems, and that the infection recedes without any further outbreak at the community level.

While the current health infrastructure, including the provision of ICUs and nursing staff, seem intact, health systems should prepare ICUs and be ready to manage patients with severe symptoms and complications at least until cases are brought under control in small clusters. The nursing populations across GCC countries are predominantly expatriates from South and South East
Asia and Africa. Media reports show trends of return migration of expatriate front-line health workers to their home countries since the pandemic started. Further investigation is needed reflecting on the demographic and socioeconomic data related to COVID-19. Unfortunately, we could not explore population-level characteristics such as age, sex, nationality and socioeconomic status due to lack of data.

International travel restrictions including flight suspensions and quarantine measures can help reduce the infection rates as well as enable systems to better coordinate appropriate public health response within countries. ${ }^{29} \mathrm{In}$ December 2020, all GCC countries have rolled out mass COVID-19 vaccination campaigns. Alongside inoculating people with COVID-19 vaccine, public health promotion should be intensified, providing clear information, education and communication such as the need to maintain social distancing, infection prevention through sanitation and hygiene, proper understanding of the modes of infection spread and management of symptoms. The lack of proper risk communication and the ability to mitigate transmission in small populations highlight the need for strengthening public health expertise and leadership within the health system.

In the longer term, GCC countries need to address the major challenge of health inequity. There is evidence to suggest that expatriate workers, being the most vulnerable economically, die at younger age compared with native Arab population. It is essential to provide expatriate populations with appropriate health coverage, insurance and living standards to reduce the burden of future epidemic outbreaks.

Equally important is the need to strengthen capacity and investment in pandemic research and ensure monitoring systems to collect systematic data on infectious diseases. Alongside basic science research, we need to apply artificial intelligence, machine learning and data sciences to understand the complexity and uncertainty of the COVID-19 pandemic. ${ }^{30-33}$ In addition, concerted efforts are needed to strengthen behavioural, social and cost-benefit economic analyses of government interventions to understand the impact of COVID-19 management and response. Finally, it is important for GCC countries to share a common data repository on critical health and health systems indicators, enabling access to the broader scientific community.

\section{CONCLUSION}

Our study demonstrates evidence of considerable variations in COVID-19 trajectory across GCC countries. Although these countries have managed to initially flatten the epidemiological curve by early August, trends since November 2020 show potential new wave of infections, especially in countries which had relatively lower number of confirmed cases. The pandemic continues to spread in GCC countries but predicted to recede over by August 2021, provided the existing infection control measures, population testing and data monitoring systems continue effectively and consistently 
across all countries. Current health infrastructure including the provision of ICUs and nursing staff seem adequate, but health systems should be alert and keep the ICUs ready to manage critically ill patients.

\section{Author affiliations}

${ }^{1}$ Department of Statistics, Ministry of Higher Education, Muscat, Sultanate of Oman ${ }^{2}$ Centre of Studies and Research, Ministry of Health, Muscat, Sultanate of Oman ${ }^{3}$ Department of Computer Science, Sultan Qaboos University, Muscat, Sultanate of Oman

${ }^{4}$ Strategy and Planning, Oman Medical Speciality Board, Muscat, Sultanate of Oman ${ }^{5}$ Social Statistics and Demography, and Centre for Global Health and Policy, University of Southampton, Southampton, UK

Contributors All authors contributed substantially to the preparation of the manuscript, including design, analysis and interpretation, and revising the article for important intellectual content. AKA-Aa, SP and AAA-M conceived the idea and wrote the first draft of the paper. AAA-H and AKA-Aa conducted the literature review. Both AKA-Aa and AAA-H contributed equally to preparing the database and conducting the statistical analysis, with technical support from AKA-Ab and SP. AKA-A, AAA-H and SP interpreted the findings. SP and AAA-M revised the draft for intellectual content.

Funding The study received funding from the Research Council, Sultanate of Oman (reference: TRC/CRP/MoHE/COVID-19/20/04).

Competing interests None declared.

Patient consent for publication Not required.

Provenance and peer review Not commissioned; externally peer reviewed.

Data availability statement Data are available in a public, open access repository. Data used for the analysis are available in the public domain in anonymous aggregate format for research use. The list of data sources is available in the References.

Supplemental material This content has been supplied by the author(s). It has not been vetted by BMJ Publishing Group Limited (BMJ) and may not have been peer-reviewed. Any opinions or recommendations discussed are solely those of the author(s) and are not endorsed by BMJ. BMJ disclaims all liability and responsibility arising from any reliance placed on the content. Where the content includes any translated material, BMJ does not warrant the accuracy and reliability of the translations (including but not limited to local regulations, clinical guidelines, terminology, drug names and drug dosages), and is not responsible for any error and/or omissions arising from translation and adaptation or otherwise.

Open access This is an open access article distributed in accordance with the Creative Commons Attribution Non Commercial (CC BY-NC 4.0) license, which permits others to distribute, remix, adapt, build upon this work non-commercially, and license their derivative works on different terms, provided the original work is properly cited, appropriate credit is given, any changes made indicated, and the use is non-commercial. See: http://creativecommons.org/licenses/by-nc/4.0/.

ORCID iD

Sabu S Padmadas http://orcid.org/0000-0002-6538-9374

\section{REFERENCES}

1 Zhu N, Zhang D, Wang W, et al. A novel coronavirus from patients with pneumonia in China, 2019. N Engl J Med 2020;382:727-33.

2 Zhou P, Yang X-L, Wang X-G, et al. A pneumonia outbreak associated with a new coronavirus of probable bat origin. Nature 2020;579:270-3.

3 World Health Organization. Coronovirus disease 2019. situation Report-72. Geneva: World Health Organization, 2019. https://apps. who.int/iris/bitstream/handle/10665/331685/nCoVsitrep01Apr2020eng.pdf

4 Wuhan coronavirus (2019-nCoV) global cases: operations dashboard. Johns Hopkins CSSE. Available: https://gisanddata. maps.arcgis.com/apps/opsdashboard/index.html\#/bda7594740fd 40299423467b48e9ecf6 [Accessed 20 Feb 2021].

5 Mahmoudi MR, Heydari MH, Qasem SN, et al. Principal component analysis to study the relations between the spread rates of COVID-19 in high risks countries. Alexandria Engineering J 2021;60:457-64.
6 Oloomi SA, Malayer MA, MOSAVI A. Trends of COVID-19 (coronavirus disease) in GCC countries using SEIR-PAD dynamic model. MedRxiv 2020.

7 Roser M, Ritchie H, Ortiz-Ospina E, et al. Coronavirus pandemic (Covid-19). our world in data. Available: https://ourworldindata.org/ coronavirus [Accessed 18 Feb 2021].

8 Coronavirus pandemic counts MAP (COVID-19) for the cooperation Council for the Arab countries of the Gulf (GCC). GCC-Stat. Available: https://gccstat.org/en/covid-19-en [Accessed 28 Feb 2021].

9 Alandijany TA, Faizo AA, Azhar El. Coronavirus disease of 2019 (COVID-19) in the Gulf cooperation Council (GCC) countries: current status and management practices. $J$ Infect Public Health 2020;13:839-42.

10 Nasir MA, Al-Emadi AA, Shahbaz M, et al. Importance of oil shocks and the GCC macroeconomy: a structural var analysis. Resources Policy 2019;61:166-79.

11 El-Saharty S, Kheyfets I, Herbst CH, et al. The GCC countries response to Covid-19. fostering human capital in the Gulf cooperation Council countries, 2020: 39-57.

12 Gulf Cooperation Council Statistics, GCC-STAT, 2020. Available: https://www.gccstat.org/en [Accessed 28 Feb 2021].

13 Rahim HFA, Sibai A, Khader Y, et al. Non-communicable diseases in the Arab world. Lancet 2014;383:356-67.

14 SW N, Zaghloul S. Ali S, Popkin BM. The prevalence and trends of overweight, obesity and nutrition-related non-communicable diseases in the Arabian Gulf states. Obesity Rev 2010;12:1-13.

15 Uddin M, Mustafa F, Rizvi TA, et al. SARS-CoV-2/Covid-19: viral genomics, epidemiology, vaccines, and therapeutic interventions. Viruses 2020;12:526.

16 Tolles J, Luong T. Modeling epidemics with compartmental models. JAMA 2020;323:2515-6.

17 Mwalili S, Kimathi M, Ojiambo V, et al. SEIR model for COVID-19 dynamics incorporating the environment and social distancing. BMC Res Notes 2020:13:1-5.

18 Harko T, Lobo FSN, Mak MK. Exact analytical solutions of the Susceptible-Infected-Recovered (SIR) epidemic model and of the SIR model with equal death and birth rates. Appl Math Comput 2014;236:184-94.

19 Sedaghat A, Oloomi SAA, Malayer A, et al. Coronavirus (COVID-19) outbreak prediction using epidemiological models of Richards Gompertz logistic Ratkowsky and SIRD 2020.

20 He S, Peng Y, Sun K. SEIR modeling of the COVID-19 and its dynamics. Nonlinear Dyn 2020;101:1667-80.

21 Murray JD. Mathematical biology: an introduction. USA: Springer, 2002.

22 Harir A, Melliani S, El Harfi $\mathrm{H}$, et al. Variational iteration method and differential transformation method for solving the SEIR epidemic model. Int J Diff Equat 2020;2020:1-7.

23 Pérez F, Granger BE. A system for interactive scientific computing, computing in science and engineering. IPython 2007:9:21-9.

24 Henri F. Infectious disease modelling: fit your model to coronavirus data, 2020. Available: https://towardsdatascience.com/ infectious-disease-modelling-fit-your-model-to-coronavirus-data2568e672dbc7 [Accessed 10 Jul 2020]

25 WHO Adaptt Surge Planning Support Tool. Regional office for Europe. Geneva: World Health Organization, 2020. https://www.euro. who.int/en/health-topics/Health-systems/pages/strengthening-thehealth-system-response-to-covid-19/surge-planning-tools/adapttsurge-planning-support-too

26 Un OCHA humanitarian data exchange, 2021. Available: https://data humdata.org/dataset/acaps-covid19-government-measures-dataset [Accessed 27 Feb 2021]

27 Ebrahim SH, Memish ZA. Saudi Arabia's drastic measures to curb the COVID-19 outbreak: temporary suspension of the Umrah pilgrimage. J Travel Med 2020;27:taaa029.

28 Algaissi AA, Alharbi NK, Hassanain M, et al. Preparedness and response to COVID-19 in Saudi Arabia: building on MERS experience. J Infect Public Health 2020;13:834-8.

29 Wells CR, Sah P, Moghadas SM, et al. Impact of international travel and border control measures on the global spread of the novel 2019 coronavirus outbreak. Proc Natl Acad Sci U S A 2020;117:7504-9.

30 Alimadadi A, Aryal S, Manandhar I, et al. Artificial intelligence and machine learning to fight COVID-19. Physiol Genomics 2020;52:200-2

31 Naudé W. Artificial intelligence vs COVID-19: limitations, constraints and pitfalls. Al Soc 2020;35:761-5.

32 Pinter G, Felde I, Mosavi A, et al. COVID-19 pandemic prediction for Hungary; a hybrid machine learning approach. Mathematics 2020;8:890.

33 Ardabili SF, Mosavi A, Ghamisi P, et al. COVID-19 outbreak prediction with machine learning. Algorithms 2020;13:249. 